Büscher, M., Kerasidou, X., Petersen, K. and R. Oliphant (in press). 'Networked Urbanism and Disaster', in Freudendal-Petersen, M. and Kesselring, S. (Eds). Networked Urban Mobilities. Springer.

\title{
Networked Urbanism and Disaster
}

Monika Büscher, Xaroula Kerasidou, Katrina Petersen, Rachel Oliphant

In a world of networked urbanism, where people affected by disaster connect intensively with each other, the media and emergency agencies, why do warnings go amiss? Why does knowledge of risk not translate into preparedness? Why are the mobilities of information so poorly understood? In this chapter, we build on a synthesis of insights from disaster management, policy, mobilities and design research, and science and technology studies (STS) to study how these disaster-related networked mobilities create complex landscapes of communication, interdependence and responsibility that are difficult to translate into preparedness. Our analysis informs, and is informed by, research collaborations with emergency responders, engineers and technology designers with the aim of understanding and developing social and digital technologies for collaboration (Petersen et al. 2014). ${ }^{1}$ By bringing attention to new networked partnerships, we aim to provide a set of critical tools with which to consider practices of risk governance as an example of networked urbanism.

In the decade $2005-2014,1.7$ billion people were affected by disasters. Around $90 \%$ of these disasters are climate related floods, storms and heat waves, which are, with some degree of precision, predictable. Yet, even though some risks can be anticipated, residents of affected areas often do not take appropriate precautions even if they are given notice of a danger which is on top of those disasters citizens fear of the most. For example, a key action point in the latest report by the United Nations Office for Disaster Risk Reduction is to study why residents do not evacuate in time (UNISDR 2015). Similarly, despite the well-known calamity of 6.47 million internally displaced people in Syria and Afghanistan in 2014 (OCHA 2015), Europe and the world were unprepared for the refugee crisis in 2015. Information that could enhance preparedness is often not noticed or acted upon on individual and organisational levels. At the same time, information can also be too freely shared. For example, when involved in crises, the

\footnotetext{
${ }^{1}$ Two recent projects include SecInCoRe http://www.secincore.eu and BRIDGE http://www.bridgeproject.eu/en.
} 
media and bystanders frequently publicise information that can compromise the safety of victims or emergency services (e.g., BBC 2015; Oh et al. 2010).

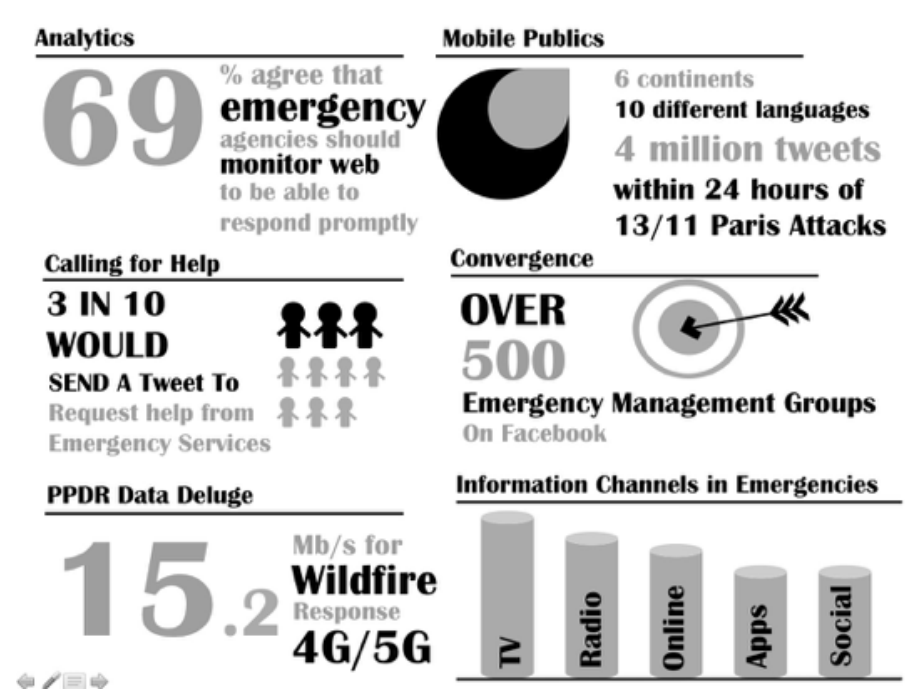

Figure 1. Networked Communications

Sources: Mashable 2011 Red Cross Pinterest board;

Ferrãos and Sallent 2015; Goel and Ember 2015

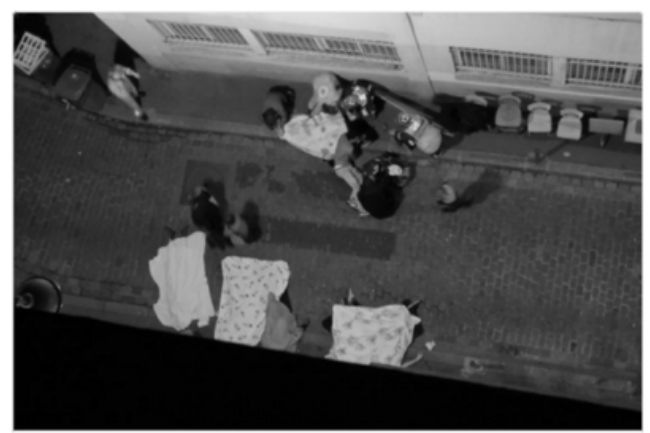

Au 90 rue de Charonne, un 7ème corps ... $y$ Follow

9:33 PM - 13 Nov 2015

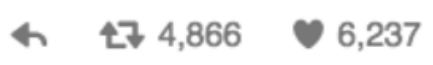

Figure 2. Mobile phone video Paris

Source: CBC News 13/11/2015,

Rosen 2015

A closer look at key dimensions of networked urbanism in disaster can help us map out some answers as to why information flows are disorganised (Figure 1). 69\% of respondents to a recent study expect emergency agencies to monitor the web for crisis-relevant information. Three in ten citizens now expect to receive help after sending an emergency tweet, even though emergency agencies strongly discourage this because they do not have the capacity to monitor social media for emergency calls (Hughes et al. 2014). Such posts might include reports from people involved in an emergency, such as images from the Paris attacks on 13 November 2015 (Figure 2) or selforganised response initiatives like \#porteouverte, where Parisians offered people affected shelter. The amount of information to monitor is vast, with four million tweets sent from six continents in the first 24 hours after the Paris attacks. And, overall, there are over 500 emergency groups on Facebook, evidence that the well-known phenomenon of convergence - people gathering at the sites of emergencies - now has a significant virtual and global dimension (Hughes et al 2008). The motivations behind these acts may be the same as they have always been (Fritz and 
Mathewson 1957): to help, to find friends and relatives, and to witness exceptional events. But the practices and expectations are changing.

Part of the reason for these transformations is that online, digital apps and social media have become established emergency information channels. Unlike traditional TV and radio, digital media afford many-to-many communications, live documentation and direct dialog, raising expectations for more immediate and interactive emergency communications. This informationalization of citizens' experiences, practices, and expectations in relation to disaster is accompanied by an informationalization of Public Protection and Disaster Response (PPDR) organisations (Büscher et al. 2015). Accelerating this transformation are pivotal decisions about the use of technology, such as the move to Long-Term Evolution (LTE) wireless high-speed data and big data analytics for Public Protection and Disaster Relief taken at the end of 2015 (Ferrãos and Sallent 2015, 79; Lund 2015).

This chapter explores what it means to have networked urbanism in disasters as it draws on a range of discussions around the constitution of publics in relation to risks, resilience, and new forms of socio-technical interactions that lead to challenges to traditional forms of disaster management. We assemble conceptual resources, including 'technologies of humility' (Jasanoff, 2003), 'communities of risk' (Beck, 1999), 'networks of trust' (Mosley 2009) to think beyond top-down or bottom-up solutions to risk, instead asking questions about what it means to engage in new partnerships of risk governance.

\section{Networked Partnerships}

As the risk society has unfolded into a century of disasters (eScience 2012), it has engendered a shift in organisational and public practices around risk. Disastrous socio-technological accidents (Chernobyl, Bhopal), natural-technical disasters (Fukushima) and socio-environmental threats of the anthropocene like climate change have increased awareness of humanity's vulnerability and responsibility for risk. Modern science has lost its monopoly on knowledge and truth (Beck 1992), and diverse new publics are demanding a voice in decisions about risk. Society's

relationship with experts has become ambivalent, blaming science and technology yet still seeing it as the (only) solution. 
This has re-assembled the relationship between science, governance, the media and the public. Publics frequently constitute in relation to disaster risk. They may take shape as groupings of the directly affected (the inhabitants of New Orleans after Hurricane Katrina) or as wider groups connected to those affected (the global Haitian diaspora, who played a major role in mobilising help after the 2010 earthquake (Munro 2013)). The formation of publics around disaster risk also includes the international community, such as those bound together as media publics (who, for example, mobilised a record $\$ 14$ billion in donations after the 2004 South Asian tsunami (Older 2014)) or as activists (like the Bhopal Group for Information and Action, who have campaigned for justice for over 30 years (Fortun 2011)). A study of 22 European countries found that how these groups are involved in emergency response varies significantly (Bossong and Hegemann 2015).

The question now emerges, how should these diverse stakeholders interact? This is a focus for intense debate in disaster management, policy and social science disciplines, where difficulties in dealing with the unpredictability of disasters have undermined confidence in the more top-down approaches known as command and control. These approaches function on hierarchical divisions of responsibility and vertical lines of communication. Strategic decision makers who are not directly active at a scene make decisions about goals and tasks that coordinate the actions of others more directly involved. Responsibility for risk analysis, preparedness and response rest 'almost exclusively on organisational shoulders and the public is perceived as passive receiver of technical information' (Scolobig et al. 2015, 2). This hampers locally flexible management and diminishes the emergency services' capability to activate community resilience (Birkland 2009, 430). This is because command and control approaches operate on a deficit model; a model that assumes that the public does not have the capacity to understand or adequately respond to, disasters, echoing Lippman's distrust in the public (Plantin 2011).

Research shows that the one-way risk communication model that flows from these assumptions actively generates failures of preparedness, such as the reluctance to evacuate that concerns the UNISDR, as we mentioned at the beginning of this chapter. Warnings, in a command and control system, do not acknowledge the complex relationality of decisions about evacuating with family, 
neighbours, friends, livestock or pets and leaving property behind (White et al. 2015). Moreover, reliance on command and control approaches often produces a narrow focus on specific risks and ignores their systemic nature (Jasanoff 2010). In response to this, one of the key principles in the United Nations Sendai Framework for Disaster Risk Reduction 2015 - 2030 states: 'Disaster risk reduction requires an all-of-society engagement and partnership' (UNISDR 2015, 13). Without considering how publics form in relation to risks, it becomes difficult to simply protect and serve the public from outside and above.

Policy analysts like Scolobig and Birkland, and international institutions like the UNISDR with their Sendai Framework assume that people centred approaches can counteract these weaknesses because they leverage local knowledge, and enable a more democratic, broad-based understanding of the complexities of risks and thereby foster more effective preparedness and response. However, such approaches are also developed for economic and political reasons. The year 2011 has been characterised as the costliest year on record by Munich RE, one of the world's leading reinsurance companies (Chen et al. 2013), and there is increasing pressure to distribute some of the responsibility for risk management to individuals and communities. An example is the wildfire triage approach taken in Tasmania to manage the high unpredictability and uncertainty of wildfires and scarce public resources. Depending on the specific unfolding patterns of a wildfire, residents may be told by emergency services in real time (not in advance) that their property cannot be defend. It is their choice to prepare for this possibility in advance themselves. The authorities see such sharing of responsibility for risk management as 'an appropriate form of response due to the lack of resources that might be drawn on to guarantee a fair and equal level of protection to all citizens in a dynamic risk environment' (Scologbig et al. 2015, 6). At this juncture, contradictory ideological energies come together. On the one hand, the deepening 'institutionalised individualism' (Beck 1999, 9) represents indexes a loss of control over risk. The 'manufactured uncertainties' of Beck's 'world risk society' are beyond insurance and beyond top-down governance, and by devolving responsibility to individuals and communities, a highly unequal distribution of despair becomes, paradoxically, simultaneously structural and a matter of individual choice and responsibility. On the other hand, there is 'hope embedded in despair', as dialog and deeper engagement with residents, their local knowledge and practices creates democratic momentum for the constitution of 'communities of risk' (Beck 
1999). These are non-territorial, potentially post-national communities that share risks, responsibilities and burdens. They are political communities, often of those who have to 'live with the risks that others take' $(1999,16)$, but with the potential to make the links between those who produce and profit from risks and those who suffer the consequences more visible and amenable to debate.

On the waves created by these ideological frictions, networked approaches are emerging, particularly in urban contexts. Principles of 'netcentric' work have been developed in the Public Protection and Disaster Relief domain to 'improve the exchange of information between heterogeneous actors', (Boersma et al. 2010, 1). In the Netherlands, where Boersma and his colleagues study this approach, it is based on a break with 'established patterns of command and control ... [and] supposed to enable new networks of communication' (Boersma et al. 2010, 1). Providing better means of navigating the choppy waters of the organisational and technological transformations involved in this is not just a matter for new networked infrastructures, but also a matter of developing new practices of noticing and collaborating with diverse, dynamically assembled, relevant actors, a design avenue we develop in the SecInCoRe project.

In their review of international public-private partnerships, Chen et al. (2013) identify eight different types of collaborations, three of which involve publics. Firstly, government-community collaborative resilience building seeks to utilise informal social networks. One example is the US Federal Emergency Management Agency’s ‘Whole Community Approach to Emergency Management' (FEMA 2011), which follows three core principles: 'Understanding and meeting the actual needs of the whole community, engaging and empowering all parts of the community, and strengthening what works well in communities' (FEMA 2011, 23). However, the approach misconceives community as well defined, sedentary and local when especially urban communities are mobile, fluid and globally networked (Büscher et al. 2014).

Chen et al. contrast FEMA's whole community approach with a second model of governmentcivil society partnerships, drawing an example from Cuba, where high level political commitment to resilience has informed institution of an annual hurricane exercise that involves the whole population. Integral to the Cuban 'culture of preparedness' is a 'fish-scale role 
structure' that assigns clear, permanent civil protection roles to local community members like health workers and teachers (Kapucu et al. 2012). They are responsible for local resilience planning and serve as coordinators during the exercise and in real emergencies. This creates flexible overlaps, like the scales of fish, between a local neighbourhood or community-based resilience system and the formal command and control model, which are 'integrated virtually through the minds of individual responders who operate in dual capacities' (Chen et al. 2013, 135). Other government-civil society partnerships rely on Memoranda of Agreement (MOA) or long-term arrangements, such as between the Buddhist organization Tzu Chi and the Taiwanese government. Less effective are ad-hoc coordination attempts, such as those between NGO and the Chinese government after the Wenchuan earthquake, which led to delayed distribution of resources.

Chen et al.'s third public partnership category, many-to-many network partnerships, also aims to bridge distances between different parties. Apart from official agencies and NGOs it also enrols more ephemeral mobile publics, where communities temporarily converge around issues of concern, often via digital and mobile technologies used everyday. These are of particular interest with a view to networked urbanism, as we will discuss. However, before we move into considerations of emergent mobile publics, the premises of concepts of new networked partnerships warrant closer inspection.

\section{Teething Problems?}

Some analysts describe difficulties in distributing responsibilities for risk definition and management as 'teething problems', because it requires 'individuals and communities to know the risks, face up to them, safeguard their rights, make informed choices and take an active part in decision making processes' (Scolobig et al. 2015, 4). But the question runs deeper, as experiences raise doubts over whether communities actually want to be more involved. Scolobig et al. find that, in fact, many do not. And when the different actors proceed on the basis of different (often unspoken) expectations, responsibilities can become unclear, placing communities who wrongly assume that official agencies will provide protection at greater risk, while also placing agencies who expect 'their' communities to be well prepared on treacherous ground. Through a series of case studies, Scolobig et al. reveal further difficulties of conflicting 
interests. When residents of an Italian town faced with the risk of landslides openly discussed resilience measures, it became clear that communal and individual land-owners' interests did not align and investments in preparedness measures were difficult to agree upon. This example is also indicative of a more general problem: official agencies and expert advisors often struggle to provide fit-for-purpose-information tailored to the highly differentiated interests and levels of knowledge amongst the publics that should be involved. Scolobig et al. conclude that

if official authorities are to implement effective people-centred disaster risk management, they need to become more attentive observers of social dynamics and more competent communicators, understand the implications of different reciprocal responsibility expectations, and engage in a long term relationship and dialogue with people at risk (2015, 8).

These are insightful recommendations. However, by framing conflicts of interest and communication troubles as teething problems, they enter the stage as irritants. It suggests that they should be eliminated before fruitful engagement can proceed. However, there are deeper dynamics at work that show that these 'problems' are actually inevitable, important constitutive components of the lived cooperation in networked communities of risk.

\section{Technologies of Humility}

We can use Jasanoff's STS concept of 'technologies of humility' to explore these depths of dealing with risk further. She argues that command and control attempts at 'disciplining the incalculable through sophisticated forms of calculation' enact ill-advised hubris $(2010,19)$. To counteract it, she argues, a shift from disaster risk management to democratic risk governance is necessary. This does $\underline{\text { not }}$ mean abandoning command and control. Like the policy scholars above, Jasanoff envisages public engagement as complementary to formal efforts. But there is more to a shift to risk governance than networking. In resonance with Beck's argument of a world risk society, Jasanoff shows that risk governance requires not only expert professionalism and broad-based engagement with local knowledge, but also an understanding of how vulnerability and resilience reflect and enact political choices that affect individuals and communities unequally. In her analysis, the conflicts of interest and difficulties in the recipient 
design of information that Scolobig et al. observe are not problems that must be overcome before partnerships can function. Indeed, the idea that agreement requires erasure of conflict and difference is misleading. STS research shows that science and politics often misunderstand the public (and thus itself, as Wynne (2007) states). The public (however constituted) are often in a better position to understand risks and be reflexive, because the institutions within which experts practice build upon assumptions about structures, social relations and local conditions that often do not reflect reality (see also Beck, 1999, 10). Plantin (2011) and Kuchinskaya (2012) explore this concretely with reference to the Fukushima disaster in Japan and Chernobyl, as we discuss further in relation to 'networks of trust' below. Important to note here is that gaining a richer and more broadly shared awareness or risks is not a matter of giving the public the same information the experts use and expecting the same interpretations, understandings and decisions. Different kinds of information, knowledge and decisions arise from different perspectives, and risks themselves are not objective facts but arise from within society, despite their often being treated as independent of situation and context (Wynne, 1996). Neither scientific nor local experts can provide a single truth or full picture, each provides an incomplete basis for good decisions without the other (Wynne 2007). Risk governance requires new ways of dealing with the inevitable reality disjunctures. There are multiple interpretations of risk, conflicts of interest and difficulties in communication that arise here, and approaches that address the diversity of risk perceptions as an integral feature of dealing with risks could be constructively leveraged for networked partnerships. Multiple interpretations are not irritants that must be eliminated before such partnerships can work. In resonance with such debates, participatory design scholars and practitioners explore how to shape socio-technical design processes and technologies that can enable agonist pluralism in ways that engage with, rather than erase, these practices (Storni 2013). Jasanoff's epistemological technologies of humility provide four particularly valuable conceptual resources, and we outline these briefly below to develop a deeper understanding of how more pluralist dialogues and controversies around risk and capacities for building communities of risk might be developed.

Firstly, framing risks more widely and seeking insight into multi-causal complexities instill humility. It also fosters reflection and iterative revision. Fortun's study of the mismanagement of risk in the city of Bhopal (2011) illustrates the value of this epistemological and moral 
technology: in the aftermath of the disaster at the Union Carbide India Limited company, it was not enough to consider the risk of harmful chemicals on the basis of individual substances affecting individual human bodies at a particular point in time. Interactions between multiple substances and long-term interdependencies must be taken into account, and the evaluation of risk and damage may change over time. But while framing brings out the systemic nature of risk, such enhanced circumspection does not address the relational quality of risks. Jasanoff's second technology of humility is a participatory focus on vulnerability, which develops new analytical sensitivities by contrasting practices of risk management with risk governance, echoing Beck's critique (1999). Risk management often narrowly defines categories of vulnerability on the basis of expert analysis. Risk governance, in contrast, seeks to understand vulnerability in collaboration with those who find themselves or are deemed vulnerable. This approach not only reveals a diversity of vulnerabilities, but also draws out capabilities that otherwise often go unnoticed. In the 2004 South Asian tsunami, for example, different communities coped very differently with the destruction. A focus on vulnerabilities and capacities shows that factors such as history, place and social connectedness 'play crucial roles in determining the resilience of human societies' (Jasanoff 2010, 32). Thirdly, Jasanoff shows how concentrating attention on the distribution of risk can be an effective technology of humility, because it makes clear how risks and damages follow established faultlines of inequality. Klinenberg's study of the 1995 Chicago heat wave (2002) and Hartman and Squires' research on New Orleans after hurricane Katrina (2006) show in distressing detail how these faultlines can deal death in one neighbourhood, while sustaining life in the one across the road. Together with a fourth technology of humility, deliberative learning, a focus on the unequal distribution of risk enables collective reflection and evaluation of explanations and approaches (Jasanoff 2003, 242). Deliberative learning brings to the table a form of 'social learning where the knowledge of the expert (based on formal experimentum) and that of the concerned laypeople (based on experentia) do not mutually exclude one another', a framework for interaction that resonates with the debates about knowledge in STS outlined briefly above and participatory design (Storni 2013, 52 ff).

When in 2014 the number of people displaced by conflict and persecution increased by 8.3 million, reaching a total of 59.5 million worldwide (OCHA 2015), risk management perspectives failed to raise appropriate awareness of an unfolding crisis. Technologies of humility could have 
helped frame these figures more circumspectly in relation to their complex causes and potential consequences, heightening awareness of vulnerabilities and capacities for response, and fostering consideration of the distribution of risks. Moreover, by highlighting faultlines of injustice before disaster strikes, risk governance raises hopes for the development of communities of risk (Beck, 1999). A more relational ethics of risk (Büscher et al. 2016), where 'it would not take a hurricane to make visible the plight of the poor' (Jasanoff 2010,33) or a refugee crisis to highlight a need for integrated European and global responses to displacement, would enable planning for futures where risks are addressed in more richly informed and - if not more just - more richly and broadly understood and contested ways.

These observational and normative arguments are not naive. They recognise that increased participation and transparency in risk governance can 'exacerbate rather than quell controversy' (Jasanoff 2003, 237), and they suggest a 'reasoned combination and integration of the strengths of both the techno-centric [command and control] and people-centred approaches, rather than ... complete rejection of one or the other' (Scolobig et al. 2015, 9). Moreover, concepts like communities of risk, agonist pluralism and technologies of humility are not just normative. They also describe empirical facts of new socio-technical practices of convergence, where mobile publics drive social, organisational and socio-technical innovation at the intersection of networked urbanism and disaster risk governance.

\section{Mobile Publics}

'Mobile publics' have been a defining feature of networked urbanism for a long time (Bruns 2008; Sheller 2004). They appropriate digital and mobile technologies that have become integral to social life, allowing distributed individuals to converge locally and sometimes globally around issues of concern. These new 'mobile' or 'issue publics' temporarily 'gel' together and disband when interest wanes. In response to disasters, the last decade has seen unprecedented innovation leading to a multiplicity of culturally and politically important, yet often fleeting, mobile publics.

Digital humanitarians form one of these publics. In a news interview, Sharon Reader, beneficiary communications delegate for the Red Cross, captures how the 2010 Haiti earthquake was a landmark moment in networked humanitarian disaster response: 
unique about Haiti was how much of an urban disaster [it] was. ... it hit Port au Prince and Leogane very heavily ... so you were dealing with a fairly, you know, dense population who do have access to different technologies - Internet, mobile phone ... even [in] countries like Haiti and right across Africa, this is technology that we can't afford to ignore as humanitarians (Transcribed from http://www.cbc.ca/dispatches/episode/2012/01/26/jan-26-29-from-haiti---kingstonjamaica---butare-rwanda---nicaragua/).

$60-80 \%$ of Haitians had access to a mobile phone after the earthquake, and within 48 hours a number of people came together to launch 'Mission 4636', building on a local freephone weather reporting system. The initiative allowed thousands of people to contribute reports via SMS and developed into a network of over 2000 volunteers to address calls for help where possible and to structure and translate the messages (Munro 2013). It also leveraged the fact that a globally distributed diaspora and concerned individuals converged on social media sites, using Twitter hashtags \#haiti and \#haitiquake to organise collective efforts. These 'digital humanitarians' (Meier 2015) and 'voluntweeters' (Starbird and Palen 2011) translated messages written in Kreyol, often containing slang terms for locations. Their work facilitated self-organised spontaneous volunteer efforts of mobilising self-help and resources. They also 'tagged' messages in ways that could be computationally parsed and mapped. Meier and a group of students in Boston set up the Ushahidi Haiti Project (UHP), the first global 'crisis mapping' project, training hundreds of volunteers within the first 100 hours after the earthquake (Meier 2015). And over 600 remote volunteers, mostly members of the Open Street Map community, produced a detailed map of Port au Prince and affected areas, including the location of shelters and available hospitals (Soden and Palen 2014). Together, these collaborations also produced a map of needs that was used by the Department of State Analysts for the US government interagency task force and US marines to enhance situation awareness and identify centres of gravity for the deployment of field teams (Morrow et al. 2011, Figure 3). 


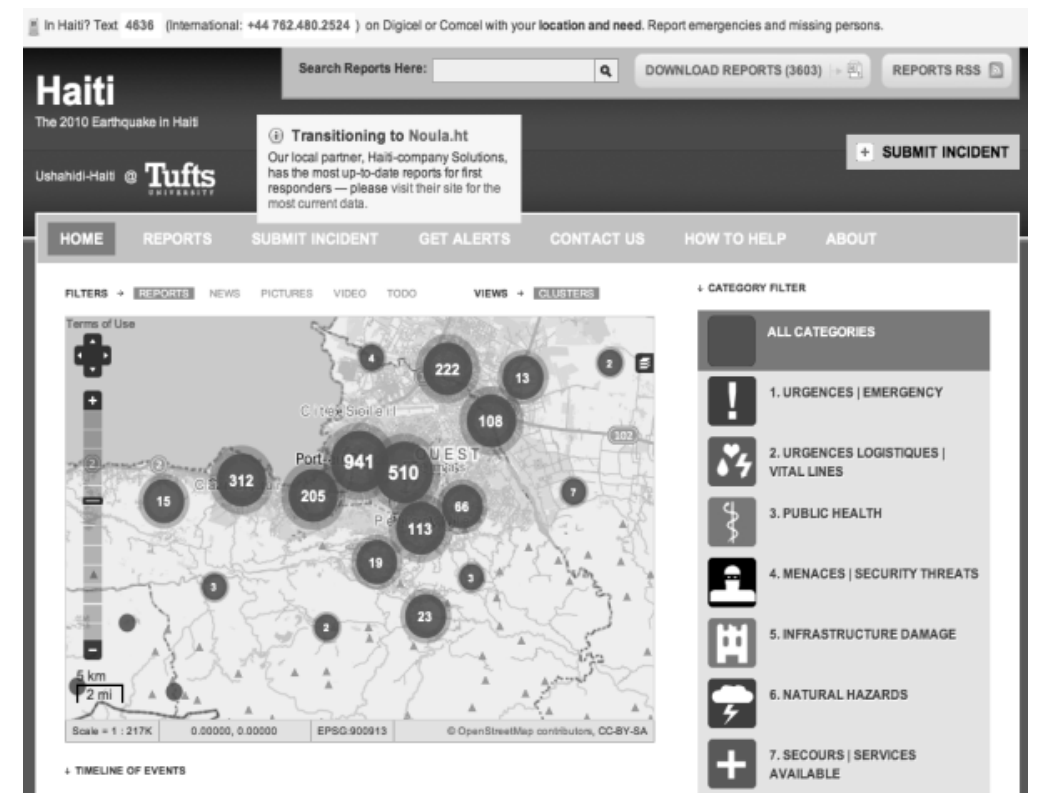

Figure 3. Ushahidi Haiti Map for Port au Prince, January 2010

Source: https://www.ushahidi.com/blog/2010/04/15/crisis-mapping-haiti-some-final-reflections

What happened in Haiti and its capital Port au Prince 'marked the start of something new' (Meier 2015). Digital humanitarianism and crisis mapping have spiralled in significance in a way that now irreversibly embeds social media in disaster management. This increasingly bridges between digital and on the ground practices and globally distributed and local participants, providing approaches that are neither purely top-down nor bottom-up. 


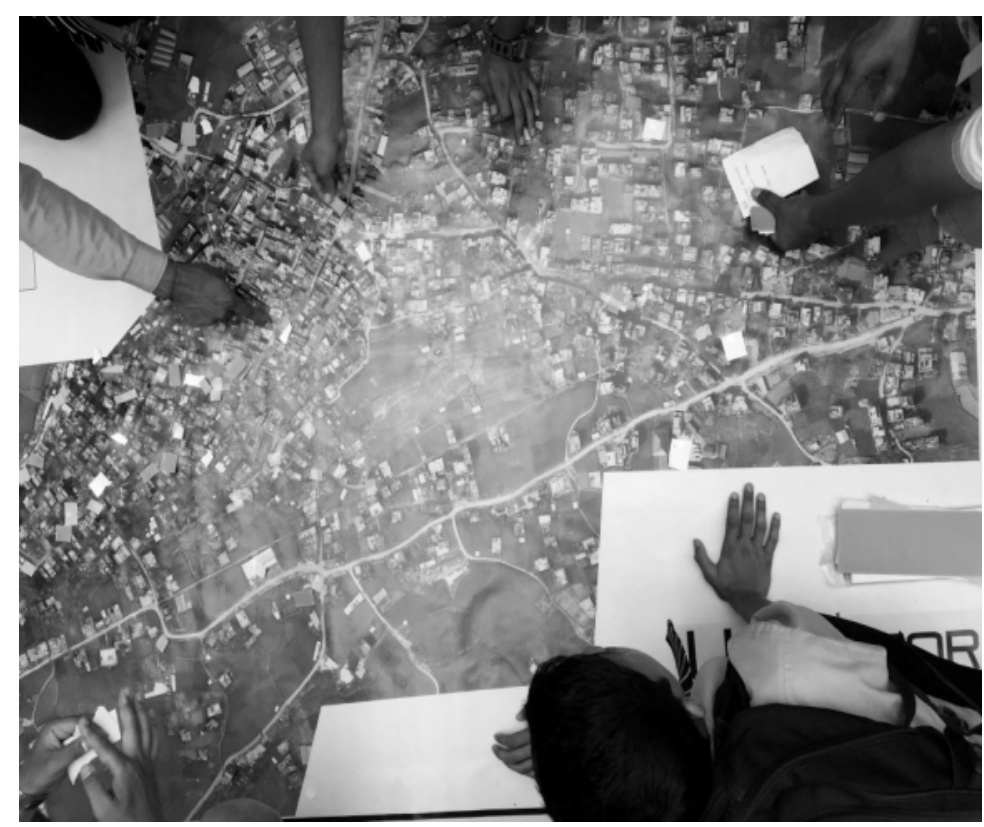

Figure 4. Local experts map local knowledge in collaboration with crisis mappers in Kathmandu. Source: http://irevolution.net/2015/11/04/crisis-mapping-nepal-aerial-robotics/

Recent networked humanitarian efforts include collaborations in Kathmandu, Nepal, where communities added local knowledge 'about the location of debris, temporary shelters, drinking water' to crowdsourced 3D crisis mapping models of the 2015 earthquake damage via paper printouts (Meier 2015, Figure 4) and Facebook's implementation of a 'Safety Check' feature, which had initially been designed and used for natural disasters. In response to the Paris attacks over 4.1 million people checked in as safe -- for their family and friends to see -- within 24 hours (Breeden 2015).

\section{Difficulties and Contradictions}

But these new publics and new ways of approaching risk are not without friction and discord. There are some fundamental changes happening. For example:

What 'Web 2.0' platforms do is shift the primary means of coordination away from hierarchical forms of organization to a network-based coordination structure, where the government is just one of the many nodes within the network (Chen et al. 2013, 137). 
However, the integration of many-to-many communications into more broad based risk governance partnerships is by no means smooth. For example, while the digital humanitarian efforts in Haiti clearly made a difference, some professional responders called it a 'shadow operation that was not part of the emergency response plan' (Morrow et al. 2011, 16), and some practitioners see serious problems with 'spontaneous volunteers' and digital humanitarians, whereas others see a lack of social, organisational and digital technologies that can support communication, cooperation and coordination. The challenges in interoperability on all of these layers are amongst the motivations for the SecInCoRe project's concept of a common information space (Pottebaum et al. 2016).

The exchange below, between senior emergency services practitioners at a recent SecInCoRe project workshop, provides a glimpse of such disagreements:

Greek Fire Service Commander: The crucial point is that if they are directed through our structures they live under our public liability insurance...If people just turn up digging, [they are] at risk themselves let alone putting other people at risk. Problem [is, they] don't want to be organised but [they've] got to be organised. It's very difficult.

German Red Cross Officer: I cannot agree on the discussion about spontaneous volunteers ... that they may be doing dangerous things themselves. The question is exactly the other way around. Why are we not able at the moment to manage that and there an information platform may be helpful cause to be honest from a Red Cross perspective we don't know ... I don't know what offers they are making, especially really special offers, what skills do we need, when do we need them and how to organise them ...

They point out how responsibility and resilience are bound to broader social infrastructures, such as the legal regulations that turn decisions into issues of liability or the institutional foundations that build not just on internal rules but also on feelings and practices of trust beyond 'safe' organisational boundaries and established professional networks. 
Moreover, accounts of digital humanitarianism often neglect wider dynamics. Mimi Sheller (2013) highlights how asymmetries of power were re-enacted through the activities of the crisis mappers in Haiti. She shows that the physical and digital influx of highly mobile international responders, from the World Bank to the crisis mappers, with their birds-eye maps coincided with a local population who mostly had neither the means nor the right to move outside the danger zone. In a similar manner, Facebook's decision to open 'Safety Check' to people affected by the Paris attacks, while not offering the same service to those affected by the Beirut bombings, which had killed over 40 people the day before, enacts asymmetries of power and ideology (Breeden 2015). Moreover, if the Facebook service was extended, it could continuously alert millions of people to who might have been (but was not) affected by disasters, stoking a culture of fear (Breeden 2015; Furedi 2006). Another question is how effective the new communication practices are. Many Haitians were unaware of the digital humanitarian effort or did not have a voice in evaluating its usefulness, and many of their calls for help could not be met either by spontaneous volunteers or official agencies (Clémenzo 2011). This highlights an element of 'communicative capitalism' where a concern with the circulation of messages eclipses commitment to dialog and (political) action (Dean 2005), as well as drawing attention to socioeconomic, political and organisational limits of disaster relief. Innumerable post-disaster reports from across the world, from Port au Prince to New Orleans, from Kathmandu to Lancaster, UK show that all-too-often there simply is not sufficient capacity made available to address the needs arising in disaster. Voicing and mapping needs more effectively and democratically does not change this. The fact that today over 60,000 Haitians are still in camps, the political system 'remains fragile, sustainable jobs are scarce, and the environment is still as vulnerable now as it was' (UNDP 2015), while many of the digital humanitarians and formal relief agencies have moved on to new crises, illustrates this difficulty.

\section{Networks of Trust and Technologies of Articulation}

However, crisis mapping activists, members of mobile publics, scholars and technology developers have developed a range of conceptual, social, organizational and digital technologies for communication, coordinating and sustaining engagement in ways that begin to work with these concerns and broader frames. Attempts at structuring digital volunteer work and crisis mapping through the UN co-founded Digital Humanitarian Network (Meier 2015) and Virtual 
Operations Support Teams or VOST (St. Denis et al. 2012) have begun to create bridges between crisis mappers and formal emergency agencies (Kaminska et al. 2015). They establish networks of trust, that is, mechanisms that combine standardisation, training, and agreed channels of communication in ways that mirror historical and sociological examples of successful public engagement in risk governance. These include engagements around air pollution in the 19th and early 20th Century (Mosley 2009) and radiation risks from Chernobyl where 'descriptive standards', 'alignment', 'unblackboxing' and 'mobile measuring' proved central to prevent risks from becoming 'twice invisible' (Kuchinskaya 2012). Experiences with such networks of trust show that, for example, accuracy of information is less important than standardised formats enabling comparison across different cities and contexts (Plantin 2011; Mosley 2009). These networks thus inevitably frame risks more broadly, also because they take measure of risks and effects in situ, they involve locals without dislodging them from their global connections. They encounter vulnerabilities and capacities for resilience at faultlines of inequality and can thereby effectively gather momentum to inject their insights and concerns into official response efforts and facilitate mutual and deliberative learning. The communities of risk that emerge are less territorial, more distributed, complexly interconnected, diverse and mobile than the communities currently considered by frameworks like FEMA's 'Whole Community Approach to Emergency Management'.

For example, in the aftermath of the Fukushima nuclear disaster which was characterised by an absence of information from public authorities, private individuals, companies and voluntary bodies initiated multiple projects of 'critical mapping' of radiation (Plantin 2011). Individuals bought or built their own Geiger counters, learnt to measure and map results, and, as their activities coalesced, they shaped official information strategies:

official information were not the only available anymore as parallel sensor-network were created; when the official data were published online, they could not be confined to nonreadable formats but were harvested to be shared and remix[ed]; finally, official data could be verified by comparing them with other sources of data, as aggregation prevailed over selection (Plantin 2011). 
Because of a lack of official efforts to inform the public and enable public engagement, the public created an alternative set of information that challenged the authority of the official sources and practices, creating distrust in the official response and forcing them to make their practices more visible and thus able to be debated and aligned to. Networks of trust are emerging as a social 'technology' that allows communities of risk to bring those who live with risk to the same table as those who produce and profit from taking them, necessitating and enabling agonistic pluralist consideration of risks. This puts an additional spin on Beck's 'boomerang effect', where those who produce certain risks (such as water or air pollution) will eventually also be affected by them (Beck 1992) ${ }^{2}$. But to practically support this, technologies of articulation are needed.

In an ethnographic study of how the emergent VOST organisation 'Humanity Road' (HR) coordinates collaboration between a globally distributed, highly fluid group of episodic volunteers, Starbird and Palen (2013) illustrate this. They identify how practices of information stewardship are central to establishing trust and coordinating information exchange. For the HR volunteers and activists this involves orchestrating reflexive, deliberative learning of best practice for producing relevant and reliable information on the fly, by doing. New volunteers are supported by leaders, who lead by virtue of the fact that they are being followed as demonstrably experienced crisis mappers, not due to some pre-assigned status of authority. Instruction proceeds through example and through tools that support articulation work, that is, the externalisation of knowledge required to competently accomplish and coordinate the work. Checklists are an example, as the one in Figure 5, formulated by participants in a 20 person HR Skype chat that evolved in response to an earthquake in Peru in 2011.

\footnotetext{
${ }^{2}$ We are grateful to the editors for drawing our attention to this connection.
} 
Peru Excerpt - Checklist - HR Useful Links- 10/28/11

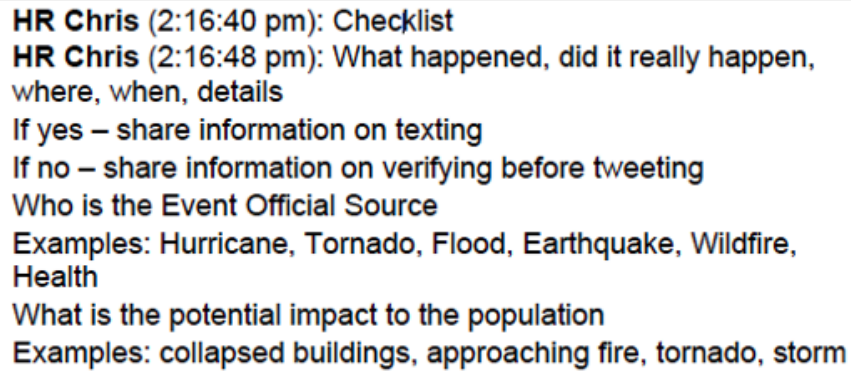

Figure 5. HR Checklist for information gathering

Starbird and Palen $(2013,498)$ explain:

The Checklist is a dynamic document, built through members' media monitoring experiences as digital volunteers, and continuously evolving as members incorporate lessons learned and leaders seek to clarify and streamline the inscribed work process... the Checklist is a resource that leaders and experienced volunteers use referentially in their own work practice and prescriptively when training others. In both capacities, the Checklist,...structure[s] the organization and its work.

The checklist is a technology of articulation in two senses. Firstly, it supports 'articulation work' (Schmidt and Bannon 1992) by putting into words the work that needs to be done to produce relevant, reliable and actionable information that will allow formal and informal responders to mobilise appropriate response measures. Secondly, as Latour (2004) shows it links discursive and material components. Like the pivoting joint that allows an articulated vehicle to turn more sharply, the checklist joins a new volunteer into the organisation, it joins the many activities and actors together as an articulated organisation, and it offers interfaces for joining digital humanitarian efforts into more widely articulated communities of risk and pluralist forms of disaster risk governance that can be more agile and more constructively agonistic and accommodating of different perspectives. 


\section{Discussion: Agile, articulated and constructively agonistic?}

Networks of trust and technologies of articulation are made in engagement with the affordances of new technologies, new partners, new publics and the complexities of risk. They are ambiguous; simultaneously sites of new forms of community, humanity and new forms of risk and conflict. In our synthesis, the characterisation of the checklist as a technology that articulates the organisation, the work and emergent communities of risk is important. An example may serve to highlight how the development of new techniques for articulation is, at least in part, driven by difficulties of understanding today's complex mobilities of information and the resulting informational topographies and, simultaneously, a constructive, innovative response to these difficulties. During the search for suspects in the days after the 2015 Paris attacks, Brussels' police imposed a lockdown of the city, engendering lively social media coverage of the events. Then 'authorities asked residents not to tweet the whereabouts of raids fearing the suspects would likely monitor police movements,' and citizens responded by tweeting cats instead (Vale 2015, Figure 6).
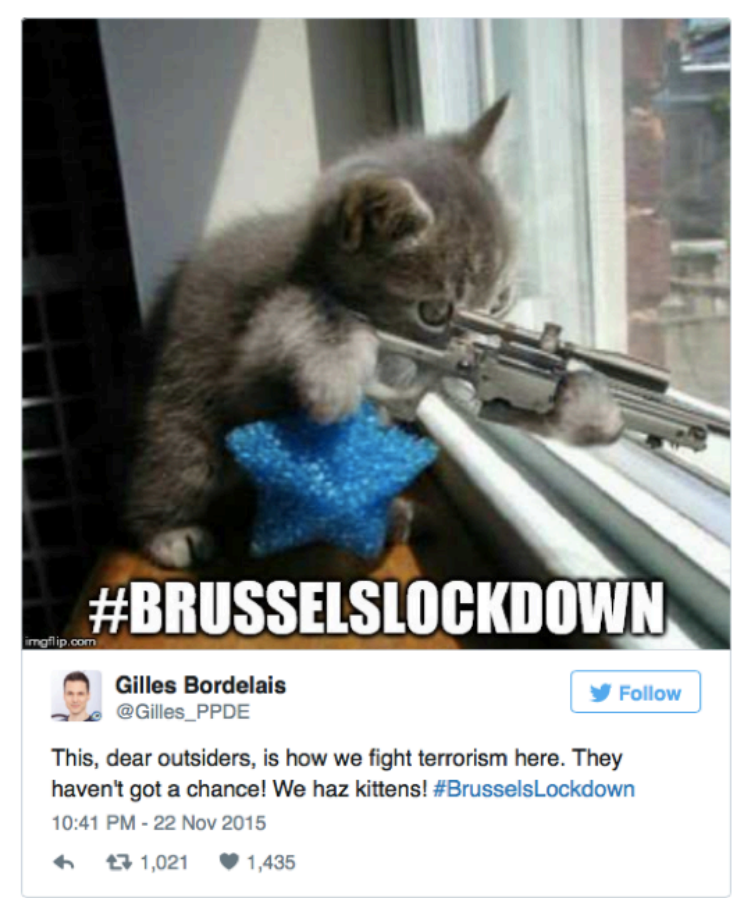
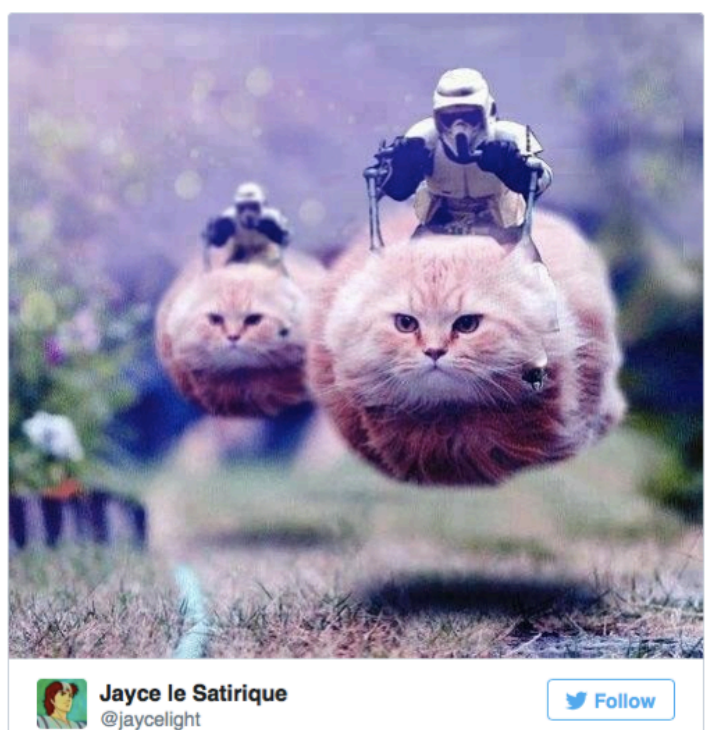

BREAKING NEWS : Belgium Police using the new $200 \mathrm{mph}$ Hovercat during terrorist operations \#BrusselsLockdown 9:10 PM - 22 Nov 2015

\& $272,088 \bullet 2,047$

Figure 6. Two of the cat pictures posted on twitter during the Brussels lockdown'

Source: Vale 2015 
Trivialising and sarcastic perhaps, but attuned to the need for more sensitive situation awareness, citizens learnt how their communications can affect and support, as well as challenge and shift, risk governance in practice. More generally, the practices we have discussed in this chapter constitute a particular form of networked urbanism, characterised by interconnected infrastructures, netcentric organisations, and self-organised mobile publics. There are still many more dimensions than we have been able to discuss, such as the 'data deluge' generated as Public Protection and Disaster Relief organisations appropriate this networked urbanism, new modes of exclusion and surveillance (Graham and Marvin 2001) as well as new forms of collective intelligence and action (Büscher et al. 2014; Lévy 1997). Still our analysis provides insights into the need for and the type of work necessary to forge new partnerships and publics. There is a need to understand communities of risk not as static communities of those affected by risks, located physically and permanently in a specific place and in need of protecting, but as socio-technical, dynamic, fleeting, distributed and mobile collectives that coalesce around risks, that interpret and contest them. The quality of new partnerships does not depend on resolving conflicts of interests and difficulties in defining and communicating about risk. Instead, they require support for communities of risk to form dynamically to express and explore the diversity of interests and interpretations, to practice agonist pluralism, connecting those who produce and assess risks with those live with and co-produce them, finding ways of leveraging technologies of humility to frame risks, vulnerabilities, and capacities in ways that seek fairness and justice, and to critically consider the distribution of risk. Developing common information spaces, networks of trust and technologies of articulation can support such practices and the mutual learning needed.

\section{Acknowledgements}

The research is part of research funded by the European Union 7th Framework Programme in the SecInCoRe project (Grant no: 261817) and BRIDGE project (Grant no.: 261817). We thank our colleagues for their inspiration, generous comments and suggestions, especially Paul Hirst, Maike Kuhnert, Michael Liegl, Jens Pottebaum and Christina Schäfer. The anonymous reviewers 
of this chapter also provided deeply insightful encouragement to engage more widely with debates of the risk society and we greatly appreciate their comments.

\section{References}

BBC News, "Paris shootings survivor sues French media," $B B C$ News, August 18, 2015, accessed January 4, 2016, http://www.bbc.co.uk/news/world-europe-33983599.

Beck, Ulrich. Risk Society: Towards a New Modernity. London: Sage, 1992.

Beck, Ulrich. World Risk Society. Cambridge: Polity, 1999.

Birkland, Thomas. "Disasters, Catastrophes, and Policy Failure in the Homeland Security Era 1," Review of Policy Research 26, no. 4 (2009): 423-438.

Boersma, Kees, Wolbers, Jeroen, \& Wagenaar, Pieter. “Organizing Emergent Safety Organizations: The travelling of the concept 'Netcentric Work' in the Dutch Safety sector," Proceedings of the 7th International Conference on Information Systems for Crisis Response and Management Conference, Seattle, USA, May (2010).

Bossong, Raphael and Hendrik Hegemann, eds. European Civil Security Governance: Diversity and Cooperation in Crisis and Disaster Management. Basingstoke, United Kingdom: Palgrave Macmillan, 2015.

Breeden, Jolie. “Are you Safe?” Disaster Research 652, November 20, 2015, accessed 4th January 2016. https://hazards.colorado.edu/article/are-you-safe-social-media-safety-checksare-useful-maybe.

Bruns, Axel. "Life beyond the public sphere: Towards a networked model for political deliberation," Information Polity 13, no. 1-2 (2008): 71-85.

Bruns, Axel, Jean Burgess, Kate Crawford, and Francis Shaw.qldfloods and@QPSMedia: Crisis Communication on Twitter in the 2011 South East Queensland Floods. Brisbane: ARC Centre of Excellence for Creative Industries and Innovation, 2012, accessed January 4, 2016. $\underline{\text { http://cci.edu.au/floodsreport.pdf. }}$ 
Büscher, Monika, Xaroula Kerasidou, Michael Liegl, and Katrina Petersen. "Digital Urbanism in Crises," In Code in the City, edited by Rob Kitchin and Sung-Yueh Perng, 163-177. London: Routledge, 2016.

Büscher, Monika, Michael Liegl and Venessa Thomas. "Collective Intelligence in Crises,” In Social Collective Intelligence. Combining the Powers of Humans and Machines to Build a Smarter Society, edited by Daniele Miorandi, Vincenzo Maltese, Michael Rovatsos, Anton Nijholt and James Stewart, 243-265. Computational Social Sciences Series: Springer, 2014.

Büscher, Monika, Sung-Yueh Perng, and Michael Liegl. "Privacy, Security, Liberty: ICT in Crises," International Journal of Information Systems for Crisis Response and Management (IJISCRAM) 6, no. 4 (2015): 76-92.

CBC News. "Dramatic video and photos from Paris attacks shared on social media," CBC News Trending, 13 November, 2015. Accessed 4 January, 2016.

http://www.cbc.ca/news/trending/paris-attacks-video-photos-social-media-1.3318626.

Clémenzo, Jean-Yves. "Ushahidi Project and Mission 4636 in Haiti: Participation, Representation and Political Economy," MA Thesis, London School of Economics, 2011.

Dean, Jodi. "Communicative Capitalism: Circulation and the Foreclosure of Politics," Cultural Politics 1, no. 1 (2005): 51-74.

eScience. "Earth faces a century of disasters, report warns," (e)Science News, 2012. Accessed 4 January, 2016.

http://esciencenews.com/sources/the.guardian.science/2012/04/26/earth.faces.a.century.disast ers.report.warns.

Federal Emergency Management Agency (FEMA). "A Whole Community Approach to Emergency Management: Principles, Themes, and Pathways for Action," FDOC 104-008-1, 2011. Accessed 4 January, 2016. http://www.fema.gov/media-library-data/20130726-181325045-0649/whole community dec2011 2 .pdf.

Ferrãos, Ramon and Oriol Sallent. Mobile Broadband Communications for Public Safety: The Road Ahead Through LTE Technology. London: Wiley, 2015.

Fortun, Kim. “Remembering Bhopal, Re-figuring Liability,” Interventions: International Journal of Postcolonial Studies 2, no. 2, 2011: 187-198. 
Fritz, Charles E. and John H. Mathewson. Convergence Behavior in Disasters: A Problem in Social Control. Washington, National Academy of Sciences, National Research Council, 1957.

Furedi, Frank. Culture of Fear Revisited. London: Continuum, 2006.

Goel, Vindu and Sydney Ember. "As Paris Terror Attacks Unfolded, Social Media Tools Offered Help in Crisis," New York Times, 14 November, 2015. Accessed 4 January, 2016.

http://www.nytimes.com/2015/11/15/technology/as-paris-terror-attacks-unfolded-social$\underline{\text { media-tools-offered-help-in-crisis.html? smid=tw-nytimes\&smtyp=cur\& } \mathrm{r}=1}$.

Hartman, Chester and Gregory Squires. There is No Such Thing as a Natural Disaster: Race, Class, and Katrina. New York: Routledge, 2006.

Hughes, Amanda, Leysia Palen, Jeanette Sutton, Sophia B. Liu and Sarah Vieweg (2008). ““'Site-seeing”' in disaster: An examination of on-line social convergence (pp. 324-333). Proceedings of the 5th International ISCRAM Conference, May 5-7, Washington, DC.

Hughes, Amanda, Lise Ann St. Denis, Leysia Palen and Kenneth Anderson. “Online public communications by police \& fire services during the 2012 Hurricane Sandy," In Proceedings of the 32nd annual ACM conference on Human factors in computing systems CHI "14, 15051514. New York, USA: ACM Press, 2014.

International Federation of Red Cross and Red Crescent Societies (IFRC). World Disasters Report 2014. International Federation of Red Cross and Red Crescent Societies, Geneva, 2014, Accessed 4 May, 2016.

http://www.ifrc.org/Global/Documents/Secretariat/201410/WDR\%202014.pdf

Jasanoff, Sheila. "Technologies of Humility: Citizen Participation in Governing Science," Minerva 41, no. 3, 2003: 223-244.

Jasanoff, Sheila. "Beyond Calculation: A Democratic Response to Risk," In G. Lakoff (Ed.), Disaster and the Politics of Intervention, 14-41. New York: Columbia University Press, 2010 .

Kaminska, Kate, Philip Dawe, Kelly Forbes, Devin Duncan, Ian Becking, Bjorn Rutten, and Darrell O’Donnell. Digital Volunteer Supported Recovery Operations Experiment. Defence Research and Development Canada, Scientific Report DRDC-RDDC-2015-R035, April, 
2015, accessed 5 May 2016. http://pubs.drdcrddc.gc.ca/BASIS/pcandid/www/engpub/DDW?W\%3DKEYWORDS+PH+WORDS+\%27Di gital+Volunteer+Supported+Recovery+Operations+Experiment\%27+ORDER+BY+Repdate/ Descend\%26M\%3D1\%26K\%3D801344\%26U\%3D1

Kapucu, Naim, Chistopher Hawkins and Fernando Rivera. Disaster Resiliency: Interdisciplinary Perspectives. London: Routledge, 2013.

Klinenberg, Eric. Heat Wave: A Social Autopsy of Disaster in Chicago. University of Chicago Press, 2002.

Knight, Ken. Facing the future. Findings from the review of efficiencies and operations in fire and rescue authorities in England. Her Majesty's Stationery Office. London, 2013.

Kuchinskaya, Olga. "Twice invisible: Formal representations of radiation danger," Social Studies of Science 43, no. 1, 2012: 78-96.

Latour, Bruno. "How to Talk About the Body? The Normative Dimension of Science Studies," Body Society 10, no. 2-3, 2004: 205-229.

Lévy, Pierre. Collective Intelligence. Mankind's Emerging World in Cyberspace. Translated by Robert Bononno. Cambridge, MA: Perseus Books, 1997.

Lund, David. "European Public-Safety Stakeholders Debate Broadband Challenges, Spectrum at PSCE Forum,” Mission Critical Communications Monday, December 14, 2015. http://www.radioresourcemag.com/Features/FeaturesDetails/FID/624

Mashable (2011) via Red Cross Pinterest board https://uk.pinterest.com/pin/508977195356660231/

Meier, Patrick. Digital Humanitarians: How Big Data Is Changing the Face of Humanitarian Response. CRC Press, 2015.

Morrow, Nathan, Nancy Mock, Adam Papendieck, and Nicholas Kocmich. "Independent Evaluation of the Ushahidi Haiti Project," Development Information systems International, 2011. Accessed 20 February, 2014. http://www.alnap.org/pool/files/1282.pdf.

Mosley, Stephen. “'A Network of Trust': Measuring and Monitoring Air Pollution in British Cities, 1912-1960," Environment and History 15, no. 3, 2009: 273-302. 
Munro, Robert. "Crowdsourcing and the Crisis-Affected Community. Lessons Learned and Looking Forward from Mission 4636," Information Retrieval 16, no. 2, 2013: 210-66.

OCHA. World Humanitarian Data and Trends 2015. Policy Development and Studies Branch, United Nations Office for the Coordination of Humanitarian Affairs, 2015. Accessed 5 May 2016. https://docs.unocha.org/sites/dms/Documents/WHDT2015 2Dec.pdf.

Oh, Onook, Manish Agrawal, and H. Raghav Rao. "Information control and terrorism: Tracking the Mumbai terrorist attack through twitter," Information Systems Frontiers, 13, no. 1, 2010: $1-11$.

Older, Malka. "When Is Too Much Money Worse Than Too Little? Giving, Aid, and Impact After the Indian Ocean Tsunami of 2004," In Recovery from the Indian Ocean Tsunami, edited by Rajob Shaw, 121-137. Tokyo: Springer Japan, 2015.

Plantin, Jean-Christophe. The Map is the Debate: Radiation Webmapping and Public Involvement During the Fukushima Issue. Paper presented at the Oxford Internet Institute, A Decade in Internet Time: Symposium on the Dynamics of the Internet and Society, September 12, 2011. Available at SSRN: http://ssrn.com/abstract=1926276 or http://dx.doi.org/10.2139/ssrn.1926276 [Accessed 8 May 2016].

Petersen, Katrina, Monika Büscher, Sarah Becklake, Vanessa Thomas, Catherine Easton, Michael Liegl, Giorgos Leventakis, Vasilis Tsoulkas, Ioannis Daniilidis, Stefanos Malliaros, Dimitris Kavallieros, Paul Hirst, Steffen Schneider, Floriana Ferrara, and Katja Firus. Overview of Disaster Events, Crisis Management Models and Stakeholders. SecInCoRe Deliverable D2.1, 2015. Accessed 4 January, 2016. http://www.secincore.eu/wpcontent/uploads/2015/09/D2.1_Overview-of-Inventory_20150831_v2.pdf.

Pottebaum, Jens, Kuhnert, Maike, Christina Schäfer, Daniel Behnke, Monika Büscher, Katrina Petersen, and Christian Wietfeld. Common Information Space for Collaborative Emergency Management. In Proceedings of the IEEE International Symposium on Technologies for Homeland Security 2016, Boston, 2016.

Red Cross Pinterest board. https://uk.pinterest.com/pin/380624605978546110/?from navigate=true 
Rosen, R. (2015). “Hostage Posts to Facebook During Paris Terrorist Attack," Heavy, 2015. Accessed 4 January, 2016. http://heavy.com/news/2015/11/paris-attack-bombing-hostagepost-social-media-facebook-twitter-benjamin-cazenoves-bataclan-eagles-death-metal/.

Schmidt, Kjeld, and Liam Bannon. Taking CSCW Seriously: Supporting articulation work. Computer Supported Cooperative Work Journal, 1(1) 1992: 7-40.

Scolobig, Anna, Tim Prior, Dagmar Schröter, Jonas Jörin, and Anthony Patt. "Towards peoplecentred approaches for effective disaster risk management: Balancing rhetoric with reality," International Journal of Disaster Risk Reduction 12, 2015: 202-212.

Sheller, Mimi. "Mobile publics: beyond the network perspective," Environment and Planning D: Society and Space 22, no. 1, 2004: 39-52.

Sheller, Mimi. "The islanding effect: post-disaster mobility systems and humanitarian logistics in Haiti," Cultural Geographies 20, no. 2, 2013: 185-204.

Lise Ann St. Denis, Amanda Hughes, and Leysia Palen. “Trial by Fire: The Deployment of Trusted Digital Volunteers in the 2011 Shadow Lake Fire," In Proceedings of the 9th International ISCRAM Conference - Vancouver, Canada, April, 2012: 1-10.

Starbird, K., \& Palen, L. (2013). Working and sustaining the virtual "Disaster Desk," In Proceedings of the 2013 Conference on Computer Supported Cooperative Work - CSCW '13 (pp. 491-502). New York, New York, USA: ACM Press.

Storni, Christiano. "Design for future uses: Pluralism, fetishism and ignorance," Nordes 5, 2013: $50-59$.

UNDP. “'Rebuilding Haiti.' Our Projects and Initiatives, United Nations Development Program,” 2015. Accessed 28 December, 2015. http://www.undp.org/content/undp/en/home/ourwork/our-projects-andinitiatives/crisis in haiti.html.

UNISDR. Sendai Framework for Disaster Risk Reduction. United Nations Office for Disaster Risk Reduction, 2015. Accessed 4 January, 2016. http://www.unisdr.org/we/coordinate/sendai-framework. 
Vale, Paul. "Brussels Lockdown Sparks Residents To Flood Twitter With Cat Pictures As Police Search For Paris Suspects," Huffington Post, November 23, 2015. Accessed 4 January, 2016. http://www.huffingtonpost.co.uk/2015/11/22/brussels-lockdown-catpictures n 8624456.html. [Accessed 8 May 2016]

White, Joanne, Leysia Palen, and Kenneth Anderson. "Digital mobilization in disaster response," In Proceedings of the 17th ACM conference on Computer supported cooperative work \& social computing - CSCW'14, 866-876. New York, New York, USA: ACM Press, 2014.

Wynne, Brian, "Misunderstood Misunderstandings: social identities and public uptake of science," In Misunderstanding Science? the public reconstruction of science and technology, edited by Alan Irwin and Brian Wynne, 19-45. Cambridge: Cambridge University Press, 1996.

Wynne, Brian. "Risk as globalizing 'democratic' discourse? Framing subjects and citizens," In Science and Citizens: Globalization and the Challenge of Engagement, edited by Melissa Leach, Ian Scoones and Brian Wynne, 66-82. London, Zed Books, 2007. 